\title{
PENINGKATAN KREATIVITAS BELAJAR IPA DENGAN PENERAPAN PROJECR BASED LEARNIG
}

\author{
Lelya Hilda', Ghifari Raihan Arafah ${ }^{2}$ \\ ${ }^{1}$ Institut Agama Islam Negeri Padangsidimpuan, ${ }^{2}$ Universitas Brawijaya Malang \\ lelya.hilda@gmail.com ${ }^{1}$, hydrateam01@gmail.com $^{2}$
}

\begin{abstract}
Students' thinking ability is still low, there is a lack of strategies, approaches or models used to improve high old thinking skills (HOTS), one of which can be used is the project base learning approach. This study aims to determine the use of the base learning project approach. This research was conducted with a quantitative approach with a quasiexperimental model, with an experimental class and a control class. The results showed the average control class was 65 and the experimental class was 80 , and from the $\mathrm{T}$ test $=$ $-24,504$ with a significance of $0.001<0.005$. These results indicate that the hypothesis is accepted.
\end{abstract}

Keywords: creative thinking; problem base learning; HOTS.

\begin{abstract}
Abstrak
Kemampuan berfikir kreatif siswa masih rendah kuragnya strategi, pendekatanb atau model yang digunkan untuk meningkatan kemampuan berfikir hight older thinking skill (HOTS), salah satu yang daapt digunakan adalah pendekatan project base learning Penelitian ini bertujuan untuk mengetahui pengaruh penggunaan pendekatan projek base learning. Penelitian ini dilakukan dengan pendekatan kuantitatif dengan model quasi eksperimen, dengan kelas eksperimen dan kelas kontrol. Hasil penelitian menunjukkan rata-rata kelas kontrol 65 dan kelas eksperimen 80, dan dari uji $\mathrm{T}$ test $=-24.504$ dengan signifikan $0.001<0.005$. Hasil ini menunjukkan bahwa hiptesis diterima.
\end{abstract}

Keywords: berfikir kreatif; problem base learning; HOTS.

\section{PENDAHULUAN}

Direktur Jenderal Pendidikan Tinggi meluncurkan surat edaran di tahun 2012, yang menyuarakan baik Perguruan Tinggi Negeri (PTN) atau Perguruan Tinggi Swasta (PTS) harus melakukan pembaharuan kurikulum. Pembaharuan tersebut dengan mewajibkan publikasi karya ilmiah sebagai salah satu persyaratan kelulusan (Wibowo, 2012). Dalam pemberlangsungan proses penulisan karya ilmiah, diketahui bahwa mahasiswa Indonesia rentan untuk melakukan sebuah tindakan plagiarism. Begitu pula, negara tetangga dan negara Eropa juga mengalami kondisi yang sama. Studi oleh mahasiswa jurusan Labour Relations dan Human Resources di Universitas Alicante di mana mendokumentasikan bahwa 90,0\% mahasiswa mengatakan mereka telah melakukan salah satu dari bentuk-bentuk cyber plagiarism (Olivia-Dumitrina et al., 2019). Sejatinya plagirisme memiliki artian sebagai 'to take somebody's else idea or 
words and use them as if they were one's own,' dikutip dari Kamus Inggris The Oxford Advanced Learner's Dictionary. Banyak hal yang dapat menjadi pemicu pelajar siswa atau mahasiswa untuk melakukan plagiarisme pada saat proses literasi berlangsung. Namun, salah satu pemicu terbesar didorong oleh lack of imagination; matinya imajinasi atau kurangnya kreativitas mahasiswa untuk menciptakan hal yang baru, baik baru secara murni ataupun baru dalam artian menghubungkan hal-hal yang sudah ada menjadi suatu yang baru.

Metode yang kurang tepat, akhrinya melahirkan anak didik yang tumpul akan kreativitas. Dalam halnya penerapan kreativitas yang berperan besar dalam Matematika dan Ilmu Pengetahuan Alam, pengajar kerap memberikan soal latihan yang sama berulang dengan tujuan agar siswa mahir dan terbiasa ketika menghadapi soal seperti itu. Akan tetapi, hal tersebut dapat mematikan proses berpikir siswa, soal dapat dijawab hanya dengan memasukkan angka ke dalam rumus. Sebagai contoh dalam materi tumbukan dan momentum dapat dilihat pada gambar di bawah ini.

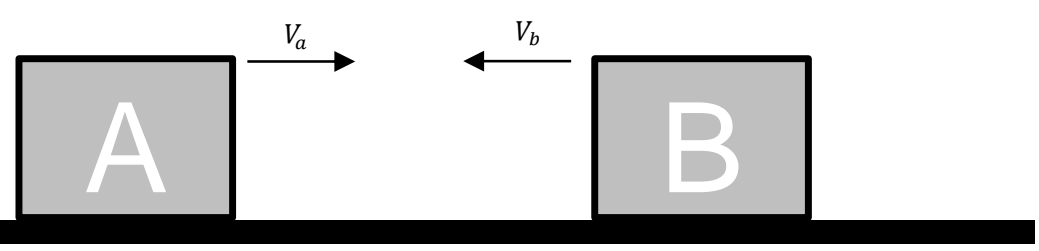

Diketahui dalam soal 2 balok dengan massa berurutan dari A ke B, $3 \mathrm{~kg}$ dan $2 \mathrm{~kg}$. Dimana balok A memiliki kecepatan awal $V_{a}=+10 \mathrm{~m} / \mathrm{s}$ dan balok B memiliki kecepatan awal $V b=-15 \mathrm{~m} / \mathrm{s}$. Dua balok saling bertumbukan lenting sempurna. Tentukanlah kecepatan balok B setelah tumbukan jika balok A memiliki kecepatan setelah tumbukan $V_{a}^{\prime}=5 \mathrm{~m} / \mathrm{s}$.

Dengan memanfaatkan hukum kekekalan momentum, maka nilai $V_{b}^{\prime}$ dapat ditentukan dengan mudah.

$$
\begin{gathered}
P=P^{\prime} \\
m_{a} v_{a}+m_{b} v_{b}=m_{a} v_{a}^{\prime}+m_{b} v_{b}^{\prime} \\
\text { (3).(+10)+(2). }(-15)=(3) \cdot(-5)+(2) \cdot v_{b}^{\prime} \\
30-30=-15+2 v_{b}^{\prime} \\
15=2 v_{b}^{\prime} \\
v_{b}^{\prime}=7.5 \mathrm{~m} / \mathrm{s}
\end{gathered}
$$

Bagaimana jika dalam balok disebutkan bahwa kedua balok tersebut identik, 
tentukan nilai $v_{b}^{\prime}$ ?

$$
\begin{gathered}
P=P^{\prime} \\
m v_{a}+m v_{b}=m v_{a}^{\prime}+m v_{b}^{\prime} \\
\text { nilai } m \text { diabaikan } \\
10-15=-5+v_{b}^{\prime} \\
-5+5=v_{b}^{\prime} \\
v_{b}^{\prime}=0 \mathrm{~m} / \mathrm{s}
\end{gathered}
$$

Pada saat kecepatan $v_{a}$ diubah menjadi $30^{\circ}$ dari sumbu x. Dengan massa A dan massa B secara berurut $5 \mathrm{~kg}$ dan $10 \mathrm{~kg}$. $v_{a}$ sebelum tumbukan sebesar $30 \mathrm{~m} / \mathrm{s}$ dan $v_{b}$ sebelum tumbukan $10 \mathrm{~m} / \mathrm{s}$. Hitunglah kecepatan setelah tumbukan jika balok A dan balok B menyatu ?

Kecapatan balok A pada sumbu x harus dicari terlebih dahulu

$$
\begin{gathered}
\frac{s a}{m i}=\cos \theta \rightarrow s a=m i \cdot \cos \theta \\
s a=30 \cdot \cos \left(30^{\circ}\right) \\
s a=30 \times 1 / 2 \\
s a=+15 \mathrm{~m} / \mathrm{s}
\end{gathered}
$$

Langkah selanjutnya dengan memanfaatkan hukum kekekalan momentum, maka nilai $v^{\prime}$ dapat ditentukan

$$
\begin{gathered}
P=P^{\prime} \\
m_{a} v_{a}+m_{b} v_{b}=m_{a} v^{\prime}+m_{b} v^{\prime} \\
m_{a} v_{a}+m_{b} v_{b}=\left(m_{a}+m_{b}\right) v^{\prime} \\
(5) \cdot(+15)+(10)(-10)=(5+10) v^{\prime} \\
75-100=(15) v^{\prime} \\
-\frac{25}{15}=v^{\prime}
\end{gathered}
$$

Ditemukan kecepatan balok setelah tumbukan dan balok tersebut menyatu adalah $\frac{25}{15} \mathrm{~m} / \mathrm{s}$ 
dan mengarah ke kiri atau searah dengan balok B.

Andaikata soal dibuat lebih kompleks, bagaimana kiranya tanggapan siswa untuk menjawab soal tersebut

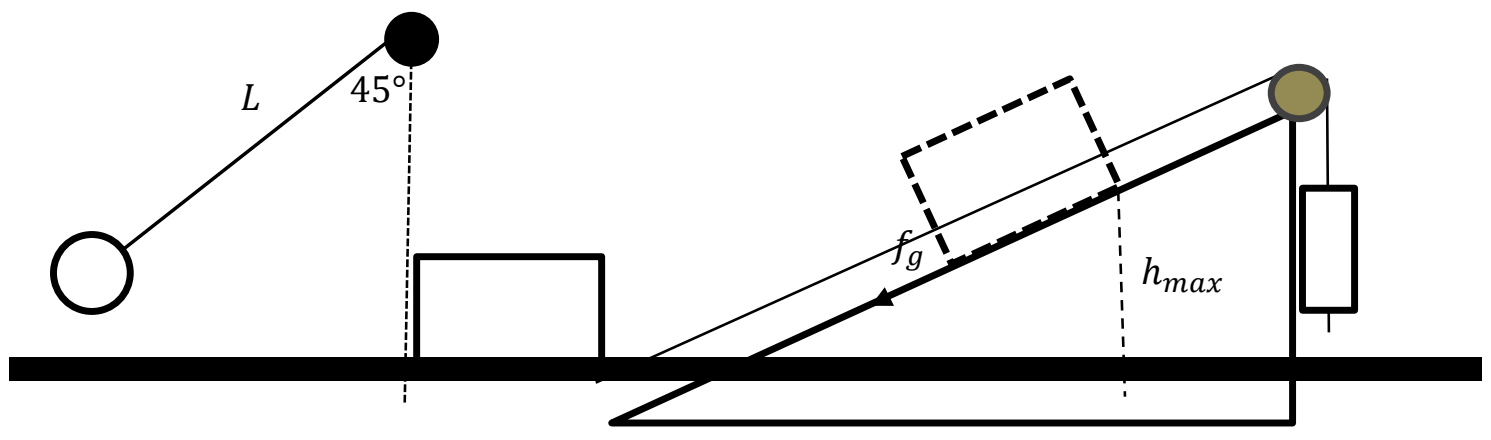

Bagaimana dengan penyelesaian soal diatas, rumus seperti apa yang harus diterapkan. Soal di atas tidak memiliki rumus jadi, sehingga apa yang harus dilakukan ?

Pemikiran siswa harus terbuka, dan perlu mengimajinasikan langkah bagaimana agar soal dapat dipecahkan. Kreativitas siswa menjadi penunjang dalam pemecahan soal berbasis HOTS (Higher Order Thinking Skill). Kreativitas menjadi perkara yang sangat penting terutama dalam menghadapi tantangan pesatnya perkembangan teknologi dan ilmu pengetahuan, sehingga menghasilkan permasalahan-permasalahan yang lebih kompleks untuk dihadapi oleh umat manusia . Permasalahan kini hadir dalam bentuk problem solving, tidak lagi mengarah kepada permasalahan soal dalam kertas, tetapi penerapan konsep dalam menyelesaikan masalah di kehidupan sehari-hari, yang menuntut pemikiran kritis dan kreativitas lebih.

Berdasarkan hasil penelitian dari Dwi Sambada (2012), berkenaan dengan hubungan kreativitas dan pemecahan masalah fisika, "Bertolak dari hasil penelitian yang telah diuraiakan, faktor potensi kreativitas dalam pelajaran fisika harus terus ditingkatkan. Usaha peningkatan mutu pendidikan fisika perlu diarahkan agar potensi ini dikembangkan, sehingga mampu mendorong dan mempergunakan kualitas berfikir siswa, misalnya mengembangkan laboratorium alam dan mengembangkan barang-barang bekas yang masih dapat dimanfaatkan (Dwi Sambada, 2012)." Dapat disimpulkan bahwa kreativitas siswa berkoleraasi baik dengan kemampuan memecahkan masalah, sehingga dapat dijadikan sebagai jalan alternatif yang dapat memperdaya siswa. Dimulai dari pendidikan non-formal dalam keluarga, dilanjutkan dengan pendidikan formal dari sekolah dasar hingga perguruan tinggi, semuanya harus diprogramkan dalam tujuan meningkatkan sifat kreatif dan inovatif (Dwi Sambada, 2012). 
Sehingga ada kebutuhan agar sistem pendidikan Indonesia berevolusi untuk mencerminkan zaman abad ke-21 daripada Revolusi Industri seperti awal kemerdekaan (Johnson \& Delawsky, 2013). Proses belajar-mengajar satu arah tidak lagi memadai untuk menghasilkan anak didik yang dapat bersaing dalam era digitalisasi seperti saat ini. Kurangnya pemahaman siswa terhadap konsep pembelajaran disebabkan selama proses tersebut siswa tidak memperhatikan dengan baik guru menjelaskan, dan lebih condong terhadap perlakuan yang menyenangkan bagi siswa. Peserta didik juga kurang aktif dalam bertanya tentang konsep yang tidak dimengerti (Fitriani et al., 2017). Apakah fenomena ini dapat disalahkan kepada siswa sepenuhnya ? Hal ini terjadi akibat kurangnya minat belajar siswa dalam kelas yang terkesan homogen, begitu-begitu saja, dan membosankan. Pada akhrinya, dengan metode lama tidak ada lagi ruang diskusi, dialektika dalam pembicaraan yang sehat berkurang, dan matinya proses berpikir - ujungnya tidak ada lagi siswa yang dapat berpikir kreatif.

Kelas tradisional yang dirasakan saat ini, sangat jelas memperlampat proses berkembang siswa. Guru sebagai pusat pengajaran menjadikan siswa sebagai orang samping - dianggap bahwa di dalam satu kelas terdapat 40 siswa, maka dalam kelas tradisional dengan metode kuno, atau pendidikan linear menghasilkan siswa dalam tingkat yang sama. Ini juga mengasumsikan bahwa setiap orang akan belajar dengan cara dan kecepatan yang sama. Siswa yang seharusnya dapat berkembang lebih baik menjadi terhambat, dan siswa yang pemalas dalam kelas dapat menjadi penghambat bagi siswa lainnya. Namun, penerapan pendidikan yang mana siswa sebagai pusat pengajaran, menunjukkan kecerdasan individu yang dibagun pelajar. Peserta didik yang terlibat dalam proses, dan bahwa mereka memiliki gaya belajar yang berbeda dan kecepatan yang berbeda dalam memperoleh pengetahuan (Uziak, 2016). Sehingga disparitas kecerdasan siswa yang satu dengan yang lainnya dapat terlihat jelas, dan guru dapat memusatkan bimbingan kepada siswa yang lebih membutuhkan. Solusi yang jelas untuk permasalahan pendidikan di Indonesia, dengan memberikan fokus yang lebih besar pada pelajar dan memungkinkan untuk menghasilkan produk yang tidak pernah dipikirkan oleh orang lain. Dengan hal tersebut kreativitas dapat dikembangkan terus menerus. Dalam kata lain, salah satu cara yang paling efektif untuk mengembangkan kreativitas adalah dengan belajar melalui proyek untuk menemukan solusi dari masalah dunia nyata, atau dalam kata lain penerapan Project Based Learning (Anazifa \& Djukri, 2017).

Pembelajaran berbasis proyek merupakan tradisi lama, terlebih dalam ruang teknikal. Namun, penerapan secara formal PjBL harus menunggu hasil akurat dalam teori 
terpercaya berdasarkan ilmu saraf dan psikologi, dari hasil klaim pengetahuan, berpikir, dan konteks belajar yang saling terkait, dan dampak dari pengalaman masa lalu (Uziak, 2016). Pembelajaran berbasis proyek (PjBL) telah dikembangkan dengan dua metode lain yang terkait erat: pembelajaran berbasis inkuiri (atau berbasis masalah) dan pembelajaran berdasarkan pengalaman. Beberapa percaya bahwa pembelajaran berbasis proyek (PjBL) adalah pembelajaran berbasis masalah (PBL) menurut definisi. Meskipun PjBL berbagi beberapa karakteristik yang tumpang tindih dengan berbasis masalah, $\mathrm{PjBL}$ dirancang untuk mengakui pentingnya standar dan evaluasi pembelajaran siswa (Johnson \& Delawsky, 2013), dan fokusnya adalah pada aplikasi, dan mungkin integrasi pengetahuan yang diperoleh sebelumnya. Pembelajaran berbasis proyek (PjBL) adalah pedagogi konstruktivis yang bermaksud membawa pembelajaran mendalam dengan memungkinkan pembelajar menggunakan pendekatan berbasis inkuiri untuk terlibat dengan masalah dan pertanyaan yang kaya, nyata dan relevan dengan topik yang dipelajari (Jalinus et al., 2017). Pembelajaran berbasis proyek berakar pada pembelajaran konstruktivis dan metode berbasis penemuan, keduanya bergantung pada proses inkuiri dan kemampuan siswa untuk merancang solusi berdasarkan perspektif dan pemikiran masing-masing.

PjBL merupakan metode pendidikan dengan menempatkn siswa sebagai pusat pembelajaran. Project Based Learning membimbing siswa agar lebih aktif untuk meningkatkan kompetensinya (Koparan \& Güven, 2008). Untuk memberikan kesempatan kepada siswa secara keseluruhan, dan lebih komprehensif dan adil dalam proses pembelajaran, PjBL diracang seperti hal tersebut, dan juga $\mathrm{PjBL}$ telah diakui sebagai pendekatan pembelajaran kolaboratif, progresif, berpusat pada siswa, interaktif, aktif dan mendalam, terutama untuk pendidikan teknik (Jalinus et al., 2017). Tugas diangkat dari permasalahan nyata, yang diharapkan anak didik dapat memecahkan masalah dengan bersandarkan sumber multidimensi. Karena ilmu sejatinya saling berhubungan satu sama lain, dalam hubungan antara kimia dan fisika akhirnya muncul ilmu pengetahuan kimia fisik, dan begitu juga untuk ilmu pengetahuan yang lainnya. Perihal ini yang diharapkan siswa dapat terapkan. Pembelajaran berbasis proyek (PJBL) memberikan kesempatan kepada siswa untuk membangun kualitas ini, serta mempelajari lebih dalam konten akademik tradisional dan memahami bagaimana penerapannya di dunia nyata (Jalinus et al., 2017).

\section{METODE PENELITIAN}

Penelitisn ini merupakan penelitian kuantitatif menggunakan metode quasi FORUM PAEDAGOGIK: Vol. 12, No. 2 (2021) P-ISSN : 2086-1915 | E-ISSN 2721-8414 || 195 
ekperimental design. Pretest-Posttest Control Group Design merupakan rancangan penelitian yang digunakan, yaitu mengguinakan kelas control dan kelas eksperimen sebagai uji coba pendekatan yang digunakan. Pretest diberikan untuk melihat kemampuan awal kedua kelas yang digunakan sebagai sampel penelitian. Kelas eksperimen diberikan dengan menerapkan pendekatan Problem Base Learning dan kelas control dengan menggunakan pendekatan konvensional pendekatan yang masih berpusat pada guru.

Hasil tes pretest dan posttest digunakan untuk menguji hipotesis, dengan rincian sebagai berikut :

H0: $\mu 1=\mu 2$ : Kemampuan mahasiswa dalam berfikir kreatif yang diajar dengan pendekatan problem base learning sama dengan yang diajar dengan pendekatan konvensional

H1: $\mu 1>\mu 2$ : Kemampuan mahasiswa dalam berfikir kreatif yang diajar dengan pendekatan problem base larnong lebih baik daripada yang diajar dengan pendekatan konvensional (Tambunan, 2020)

\section{HASIL DAN PEMBAHASAN}

Hasil test berfikir kreatif yang diberikan baik dalam kelas control maupun kelas eksperimen terlihat pada tabel berikut:

Tabel 1. Hasil Berfikir Kreatifi Mahasiswa

\begin{tabular}{|c|c|c|c|}
\hline No & Indikator & Pretest & Postest \\
\hline 1 & $\begin{array}{l}\text { Mengidentifikasi sifat- } \\
\text { sifat suatu konsep dan } \\
\text { mengenal syarat yang } \\
\text { menentukan suatu } \\
\text { konsep }\end{array}$ & 67 & 85 \\
\hline 2 & $\begin{array}{l}\text { Membandingkan dan } \\
\text { membedakan konsep- } \\
\text { konsep }\end{array}$ & 65 & 80 \\
\hline 3 & $\begin{array}{l}\text { Keluwesan } \\
\text { (flexibility) meliputi } \\
\text { menghasilkan } \\
\text { gagasan, jawaban, atau } \\
\text { pertanyaan yang } \\
\text { bervariasi }\end{array}$ & 65 & 78 \\
\hline 4 & $\begin{array}{lr}\text { Kelancaran } & \text { yaitu } \\
\text { siswa } & \text { Mampu } \\
\text { menguraikan } & \text { suatu } \\
\text { permasalahan } & \text { secara }\end{array}$ & 64 & 79 \\
\hline
\end{tabular}




\begin{tabular}{|l|l|l|l|}
\hline 5 & lengkap & & \\
\hline & $\begin{array}{l}\text { Menggunakan model, } \\
\text { diagram dan simbol- } \\
\text { simbol untuk } \\
\text { merepresentasikan } \\
\text { suatu konsep }\end{array}$ & 64 & \\
\hline Rata-rata & 65 & 80 \\
\hline
\end{tabular}

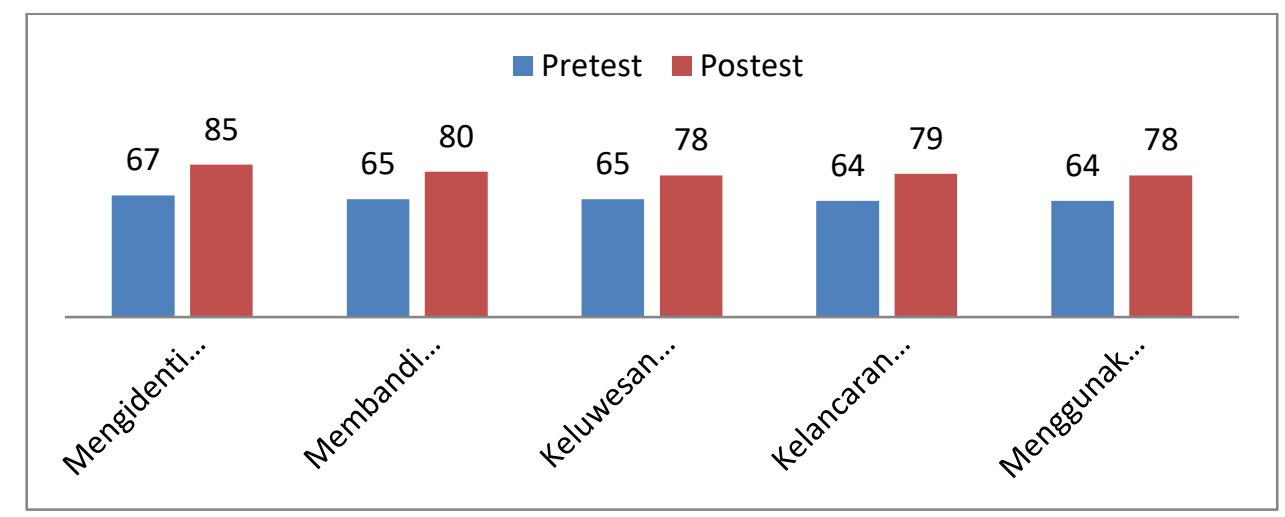

Gambar 1. Penilain Berfikir Kreatif

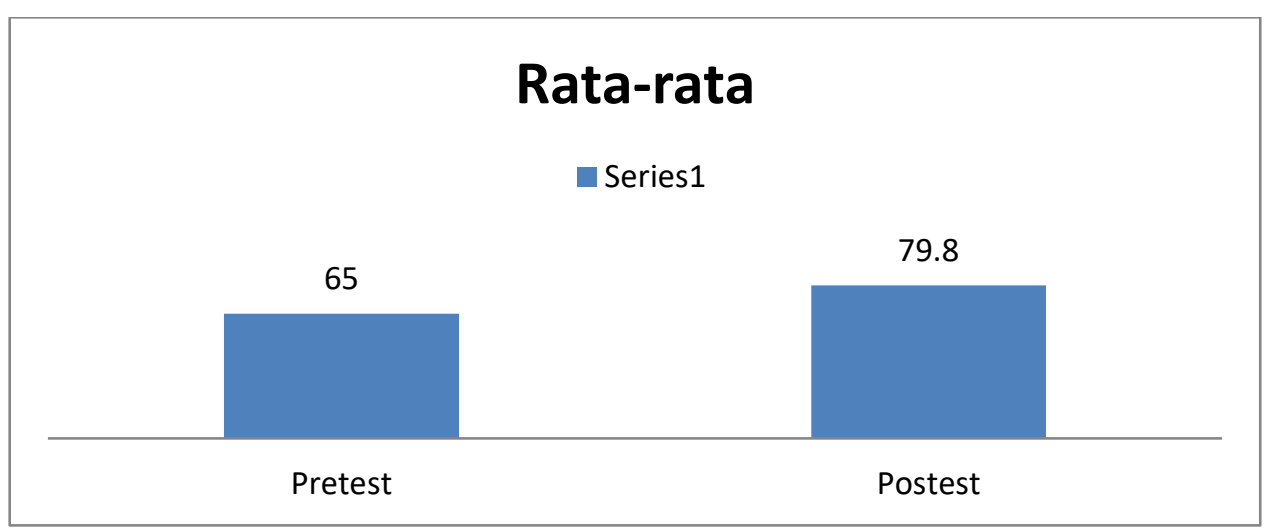

Gambar 2 . Ratra-rata pretest dan posttest dalam tes berfikir kreatif

Tabel 2. Deskripsi hasil penelitian

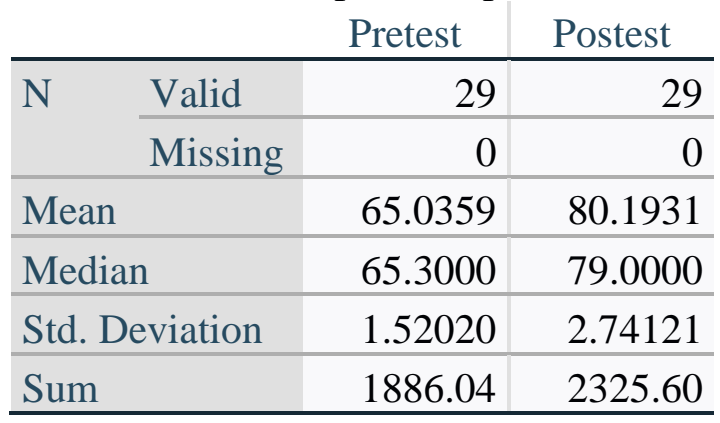




\begin{tabular}{cccccccc}
\multicolumn{9}{c}{ Paired Samples Test } \\
& Lower & upper & T & df & \multicolumn{1}{c}{ signifikan } \\
\hline 1 & pretest- postest & .16 .42430 & -13.89018 & -24.504 & 28 & $<.001$ & $<.001$ \\
\hline
\end{tabular}

\section{Pembahasan}

Hasil penelitian mnenunjukkan ada peningkatan berfikir kratif mahasiswa dengan mengunnakan pendekatan projek base learning dalam pembelajaran IPA. Peningkatan yang dicapai mencapai $23 \%$ dibanding dengan kelas control. Dari 5 indikator berfikir kreatif memperoleh rata-rata 80 untuk eksperimen dan rata-rata 65 untuk kelas kontrol.

Hasil uji $\mathrm{t}$ test menunjukan $\mathrm{t}=-24.504$ dengan signifikan $0.001<0.005$, yang menunjukkan bahwa hipotesa ada pengaruh penggunaan pendejatan problem base learning terbukti.

Hasil peneliitan yang dilakukan Tambunan, (2020) menunjukkan hasil yang sama bahwa dengan projek base learning terjadi peningkatan berfikir kreatif siswa. Hal yang sama juga diperoleh dari hasil penelitian Fitrina et al.,(2016) kemampuan berpikir kreatif matematis siswa yang mengikuti pembelajaran project based learning dan siswa yang mendapatkan pembelajaran konvensional. Instrumen yang digunakan berupa tes berupa soal essay yang diberikan pada saat pretest dan posttest untuk melihat peningkatan, serta tentang lembar aktivitas siswa yang akan menjadi acuan dalam debat. Berdasarkan analisis data statistik dengan menggunakan uji-t menunjukkan bahwa peningkatan kemampuan berpikir kreatif siswa yang memperoleh pembelajaran matematis pembelajaran berbasis proyek lebih baik dibandingkan siswa yang memperoleh pembelajaran konvensional. Berdasarkan analisis data statistik dengan menggunakan Two-Way ANOVA menunjukkan bahwa tidak terdapat interaksi antara model pembelajaran dengan tingkat kemampuan siswa terhadap peningkatan kemampuan berpikir kreatif.

- Sedangkan hasil penelitian yang dilakukan Sari \& Wulanda, (2019) bahwa pendekatab projek base larning yang dapat mendukung optimalisasi pembelajaran. Dengan melihat keefektifan lembar kerja mahasiswa berbasis proyek dalam meningkatkan kemampuan berpikir kreatif mahasiswa. Hasil penelitian ini menunjukkan 
bahwa lembar kerja mahasiswa berbasis proyek efektif dalam meningkatkan kemampuan berpikir kreatif mahasiswa.

\section{KESIMPULAN}

Hasil penelitian menunjukkan bahwa pendekatan problem base learning dapat meningkatan berfikir kreatif siswa. Dalam menghadapi era gobalisasi kemampuan berfikir kreatif merupakan salah satu indikator yang harus diasah untuk mengembangkan kemampuan berfikir tingkat tinggi siswa (HOTS). Rata-rata kemampuab berfikir siswa 80, dalam skala sangat baik dan terdapat pengaruh signifikan dengan menggunakan pendekatan problem base learnig.

\section{REFERENSI}

Anazifa, R. D., \& Djukri. (2017). Project- based learning and problem- based learning: Are they effective to improve student's thinking skills? Jurnal Pendidikan IPA Indonesia, 6(2), 346-355. https://doi.org/10.15294/jpii.v6i2.11100

Dwi Sambada. (2012). Peranan Kreativitas Siswa Terhadap Kemampuan Memecahkan Masalah Fisika Dalam Pembelajaran Kontekstual. Jurnal Penelitian Fisika Dan Aplikasinya (JPFA), 2(2), 37-47.

Fitriani, N., Gunawan, G., \& Sutrio, S. (2017). BERPIKIR KREATIF DALAM FISIKA DENGAN PEMBELAJARAN CONCEPTUAL UNDERSTANDING PROCEDURES (CUPs) BERBANTUAN LKPD. Jurnal Pendidikan Fisika Dan Teknologi, 3(1), 24. https://doi.org/10.29303/jpft.v3i1.319

Fitrina, T., Ikhsan, M., \& Munzir, S. (2016). Peningkatan Kemampuan Berpikir Kreatif dan Komunikasi Matematis Siswa SMA melalui Model Pembelajaran Project Based Learning Berbasis Debat. Jurnal Didaktik Matematika, 3(1), 87-95. https://doi.org/10.24815/jdm.v3i1.4753

Jalinus, N., Nabawi, R. A., \& Mardin, A. (2017). The Seven Steps of Project Based Learning Model to Enhance Productive Competences of Vocational Students. January. https://doi.org/10.2991/ictvt-17.2017.43

Johnson, C. S., \& Delawsky, S. (2013). Project-based learning and student engagement. Academic Research Interanational, 4(4), 560-571.

Koparan, T., \& Güven, B. (2008). The Effect on the 8th Grade Students' Attitude towards Statistics of Project Based Learning. European Journal of Educational Research, $3(2), 73-85$.

Olivia-Dumitrina, N., Casanovas, M., \& Capdevila, Y. (2019). Academic writing and the internet: Cyber-plagiarism amongst university students. Journal of New Approaches 
in Educational Research, 8(2), 112-125. https://doi.org/10.7821/naer.2019.7.407

Sari, D. S., \& Wulanda, M. N. (2019). Pengembangan lembar kerja mahasiswa berbasis proyek dalam meningkatkan kemampuan berfikir kreatif mahasiswa. Natural: Jurnal Ilmiah Pendidikan IPA, 6(1), 20. https://doi.org/10.30738/natural.v6i1.4073

Tambunan, H. (2020). Kemampuan Siswa dalam Pemecahan Masalah Matematika dengan Strategi Heuristik. Sepren, 1(02), 28-33. https://doi.org/10.36655/sepren.v1i02.209

Uziak, J. (2016). A project-based learning approach in an engineering curriculum. Global Journal of Engineering Education, 18(2), 119-123.

Wibowo, A. (2012). Plagiarisme merupakan perbuatan salah yang serius sebab mengambil karya orang lain dan mengakuinya sebagai karya sendiri. Tindakan plagia_risme menurunkan moral dan harkat pelaku serta berdampak pada disin_tegritas sivitas akademik karena tindakan menguti. Kesmas, Jurnal Kesehatan Masyarakat Nasional, 6(5), 195-200. 